
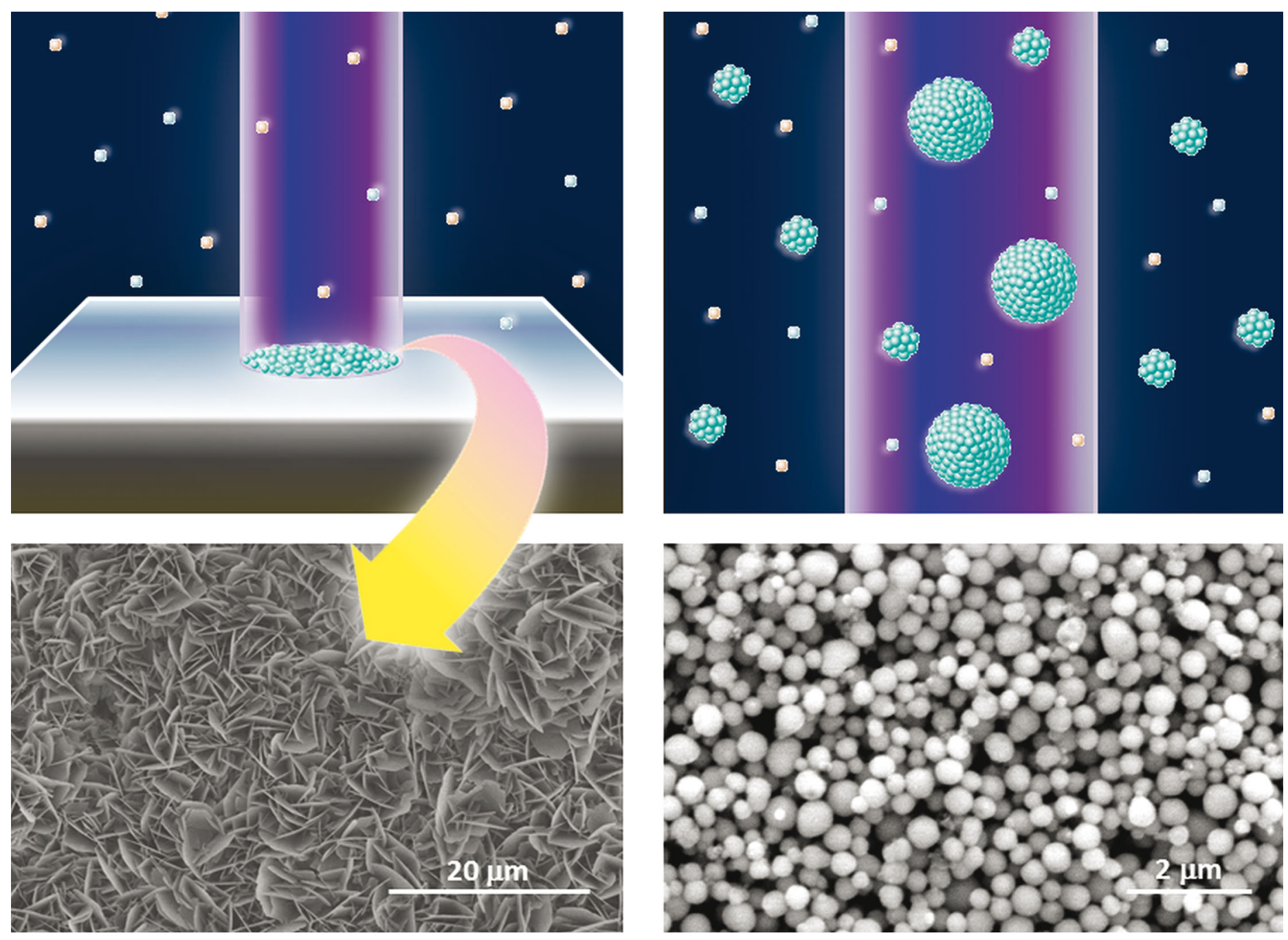

Showcasing a review by researchers at the Nanomaterials Research Institute, National Institute of Advanced Industrial Science and Technology (AIST), Japan.

Physicochemical fabrication of calcium phosphate-based thin layers and nanospheres using laser processing in solutions

New physicochemical processes have been developed for the fabrication of calcium phosphate-based thin layers (left-hand side) and nanospheres (right-hand side) via pulsed laser-mediated light-material interactions in supersaturated solutions.

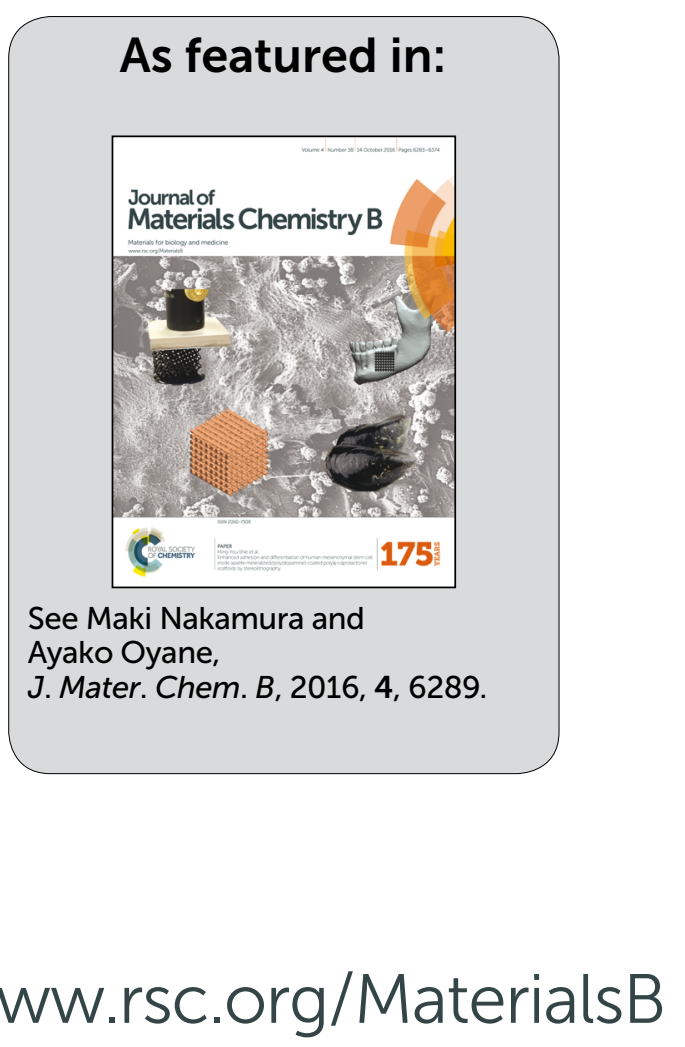


CrossMark \& click for updates

Cite this: J. Mater. Chem. B, 2016, 4,6289

Received 1st June 2016,

Accepted 15th August 2016

DOI: $10.1039 / c 6 t b 01362 g$

www.rsc.org/MaterialsB

\title{
Physicochemical fabrication of calcium phosphate-based thin layers and nanospheres using laser processing in solutions
}

\begin{abstract}
Maki Nakamura* and Ayako Oyane*
Calcium phosphate (CaP)-based thin layers and nanospheres have various potential biomedical applications. This paper describes the laser-assisted fabrication of CaP-based thin layers and nanospheres, with a focus on a new physicochemical process developed by us. This process is conducted under normal pressure and temperature in supersaturated $\mathrm{CaP}$ solutions using pulsed laser irradiation. Owing to the lightmediated solid-liquid interactions, this process enables the simple and rapid fabrication of CaPs. In addition, the physicochemical and biological properties of CaPs can be controlled by manipulating the processing conditions. Our physicochemical process provides a new tool for fabricating CaP-based thin layers and nanospheres for biomedical applications.
\end{abstract}

\section{Introduction}

\subsection{Fundamentals of calcium phosphates}

Calcium phosphates (CaPs) are the main mineral components found in human bones and teeth. They are synthesized naturally in living organisms via biomineralization and are also fabricated via artificial processes outside the human body. As already summarized in a number of recent reviews, ${ }^{1-11}$ there

Nanomaterials Research Institute, National Institute of Advanced Industrial Science and Technology (AIST), Central 5, 1-1-1, Higashi, Tsukuba, Ibaraki 305-8565,

Japan.E-mail:ma-ki-nakamura@aist.go.jp, a-oyane@aist.go.jp exist various types of CaP compounds that possess different crystalline phases, chemical formulas, $\mathrm{Ca} / \mathrm{P}$ molar ratios, and solubilities. Most CaPs are sparingly or hardly soluble in neutral water but all CaPs dissolve in acids. Among $\mathrm{CaP}$ compounds, hydroxyapatite $\left(\mathrm{HAp}, \mathrm{Ca}_{10}\left(\mathrm{PO}_{4}\right)_{6}(\mathrm{OH})_{2}, \mathrm{Ca} / \mathrm{P}=1.67\right)^{3-6}$ is the most stable and insoluble phase in the physiological environment. Moreover, HAp is similar to the mineral component found in bones and teeth. Some CaPs such as octacalcium phosphate $\left(\mathrm{OCP}, \mathrm{Ca}_{8}\left(\mathrm{HPO}_{4}\right)_{2}\left(\mathrm{PO}_{4}\right)_{4} \cdot 5 \mathrm{H}_{2} \mathrm{O}, \mathrm{Ca} / \mathrm{P}=1.33\right)^{12}$ are found as intermediate phases during biomineralization. Amorphous calcium phosphate (ACP, $\left.\mathrm{Ca}_{x} \mathrm{H}_{y}\left(\mathrm{PO}_{4}\right)_{z} \cdot n \mathrm{H}_{2} \mathrm{O}(n=3-4.5), \mathrm{Ca} / \mathrm{P}=1.2-2.2\right)^{13}$ is also a precursor of HAp and appears in the initial stage of

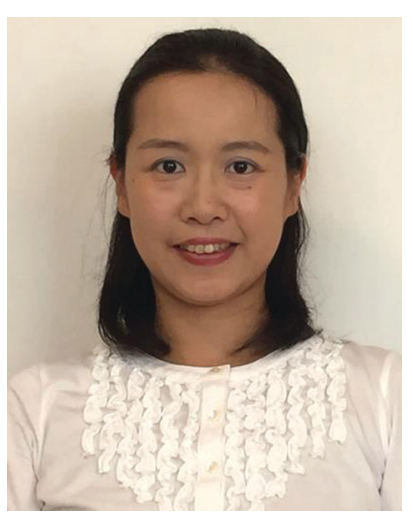

Maki Nakamura
Maki Nakamura received her doctoral degree in pharmacy from Tokyo University (Japan) in 2009. Subsequently, she joined Nanotube Research Center of National Institute of Advanced Industrial Science and Technology (AIST, Japan) as a postdoctoral fellow. In 2013, she joined Nanosystem Research Institute (currently, Nanomaterials Research Institute) of AIST as a researcher. Her research interests include nanomaterials, biomedical materials, imaging, drug delivery, and laser processing.

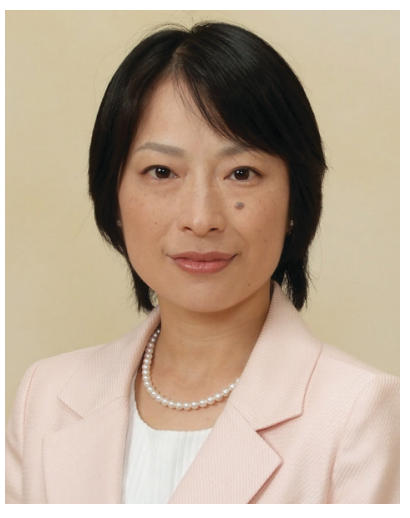

Ayako Oyane
Ayako Oyane received her doctoral degree in engineering from Kyoto University (Japan) in 2002. Subsequently, she joined AIST (Japan) as a researcher. In 2009, she was promoted to a senior researcher. Her research interests include biomineralization, biomedical materials, drug and gene delivery, tissue engineering, and laser processing. She was honoured with the Ceramic Society of Japan Award for Advancements in Ceramic Science and Technology in 2009, the Award for Young Investigator of Japanese Society for Biomaterials in 2010, and the Morita Award for Young Women Scientists from the Japanese Association of University Women in 2013. 
biomineralization. Compared with well-crystallized HAp, OCP and ACP have relatively higher solubilities.

\subsection{Biological properties and applications of CaPs}

Some CaPs, including sintered HAp and $\beta$-tricalcium phosphate ( $\beta$-TCP, $\left.\beta-\mathrm{Ca}_{3}\left(\mathrm{PO}_{4}\right)_{2}, \mathrm{Ca} / \mathrm{P}=1.5\right)$, show good biocompatibility, i.e., they are generally nontoxic and induce minimal inflammatory or foreign-body reactions. Unlike other general artificial materials, they are not encapsulated by fibrous tissues, and bond directly to the living bone tissues. This property is referred to as bone-bonding ability or osteoconductivity. On these osteoconductive CaP surfaces, bone cells adhere and proliferate, and finally a new bone is formed and interacts with the surrounding bone tissues. In addition to osteoconductivity, some CaPs such as sintered carbonate apatite and $\beta$-TCP show bioresorbability, i.e., they are dissolved in the body and replaced with the bone tissue over time. Because of these useful biological properties, CaPs in various compositions and forms have been used in orthopedic and dental applications. ${ }^{8,11,14,15}$ For example, sintered HAp, $\beta$-TCP, and $\alpha$-TCP $\left(\alpha-\mathrm{Ca}_{3}\left(\mathrm{PO}_{4}\right)_{2}, \mathrm{Ca} / \mathrm{P}=1.5\right)$ and their composites have been used as bone substitutes, bone cement powders, bone fillers, and osteoconductive coatings on implants.

Some CaPs also show high affinity for specific drugs, proteins, antibodies, and nucleic acids (DNA, RNA). In addition, the component ions (calcium, phosphate, and hydroxide ions) in CaPs are easily replaced by other inorganic ions. ${ }^{2,16-18}$ Therefore, CaPs have also been used as column beads for chromatography, ${ }^{19,20}$ adsorbents for organic and metallic pollutants, ${ }^{21,22}$ and transfection reagents for cells. ${ }^{23-25}$ In recent years, delivery of therapeutic and diagnostic agents using $\mathrm{CaP}$ nanoparticles has been intensively studied for developing multifunctional CaP-based nanocarriers. ${ }^{3,26-28}$

\subsection{CaP thin layers and nanospheres}

Bulk CaP ceramics are generally manufactured by sintering row $\mathrm{CaP}$ powder compacts. However, sintered bulk $\mathrm{CaP}$ ceramics are extremely hard and brittle; hence, they can be used only under low-load-bearing conditions. Coating thin layers of CaPs on different artificial materials (e.g., tough and strong metallic materials or soft and flexible polymeric materials) is an effective approach to produce biocompatible and osteoconductive composites that can be used under various conditions. ${ }^{10,29-33}$ Thus, the CaP coating technique is important for expanding the use and practical application of CaPs and for functionalizing the surfaces of artificial materials.

The fabrication of CaP-based nanospheres is also becoming increasingly important because of the high potential of CaPbased nanospheres as safe and biocompatible delivery carriers for therapeutic and diagnostic agents. ${ }^{3,26-28}$ CaP-based nanospheres show potential as carriers because nano-sized particles can penetrate into tiny interstices in a body, be administered by injection, travel through the bloodstream, and permeate cell membranes and blood vessel walls if particle structures and surface functionalities are appropriate. CaP carriers comprising human biomineral components have the advantages of biocompatibility, low toxicity, $\mathrm{pH}$ sensitivity (degradable under acidic conditions into serum ions), and cost-effectiveness (sources are ubiquitous elements). Owing to these potentials and advantages, CaP-based nanospheres with various compositions and structures (solid, hollow, and core-shell) have recently been developed for use in delivery carrier applications. ${ }^{34-37}$

\subsection{Fabrication of CaP thin layers and nanospheres}

Conventionally, CaP-based thin layers and nanoparticles have been fabricated by either physical or chemical process (this will be described in more detail later). Recently, we developed a new physicochemical process for the fabrication of CaP-based thin layers ${ }^{38-42}$ and nanospheres ${ }^{43,44}$ by combining a physical laser process and a chemical precipitation process. In this process, pulsed laser irradiation is performed without focusing to a metastable or labile supersaturated CaP solution to induce lightmaterial interactions at a laser-irradiated substrate surface (for thin layer fabrication) or in the entire solution (for sphere fabrication) (Fig. 1). In the process of thin layer fabrication, bulk substrates immersed in a metastable supersaturated $\mathrm{CaP}$ solution function as both a light-absorbing agent and a frame to support the CaP layer (Fig. 1, lower left). In the process of sphere fabrication, metal ions incorporated within the dispersed nano-precipitates function as light-absorbing agents in a labile supersaturated CaP solution (Fig. 1, lower right).

This review summarizes the fabrication processes of CaP-based thin layers (Section 2) and spheres (Section 3), focusing on our physicochemical process via laser processing in supersaturated CaP solutions. In this review, a nanosphere is defined as a particle with a diameter of 1-1000 $\mathrm{nm}$.
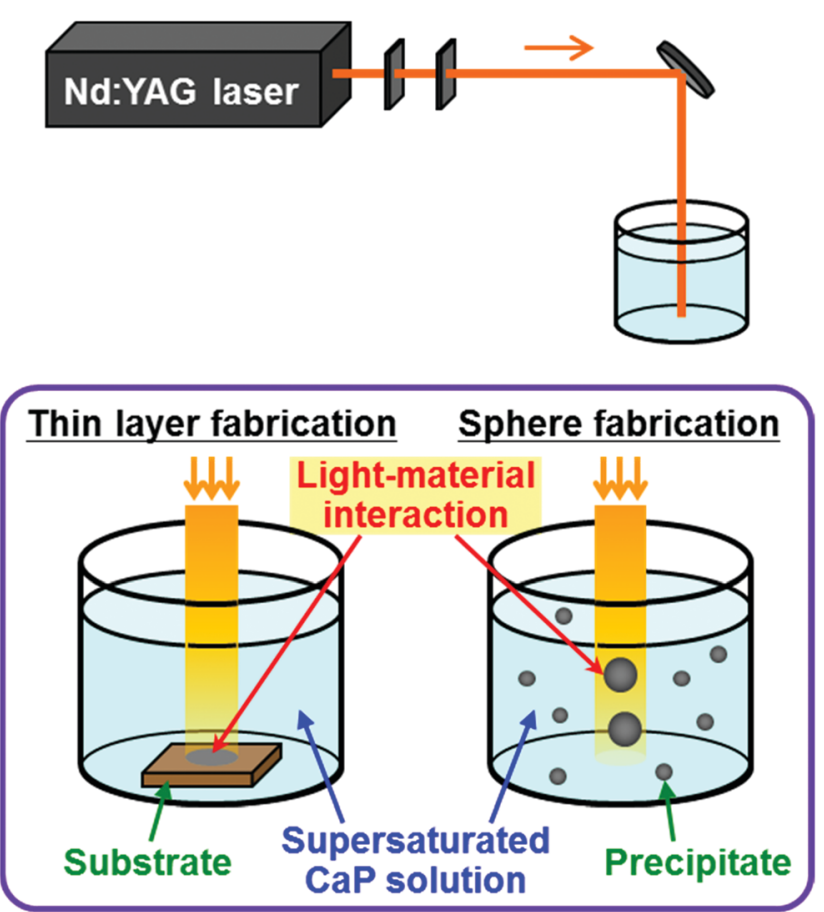

Fig. 1 Schematic illustration of our physicochemical process: laser irradiation system (upper), thin layer fabrication (lower left), and sphere fabrication (lower right). 


\section{Physicochemical fabrication of CaP-based thin layers}

\subsection{CaP coating techniques}

2.1.1 Conventional physical and chemical processes. Among CaP coating techniques, physical processes such as plasma spraying, thermal spraying, pulsed laser deposition (laser ablation), sputtering, and ion-beam assisted deposition are practical, particularly for metallic substrates because of the relatively high CaP deposition rate. ${ }^{10,29-32}$ However, these physical processes are associated with high thermal energy and often involve a risk of heat damage of substrates and decomposition of CaPs. In addition, it is difficult to incorporate heat-labile biofunctional substances (e.g., proteins) within CaP layers. On the other hand, chemical CaP coating processes such as the biomimetic process (precipitation process), alternate dipping process, electrochemical deposition, and solgel process are carried out under relatively mild conditions (low temperature and normal pressure). ${ }^{10,25,29,30,33,45}$

2.1.2 Biomimetic process: from chemical to physicochemical processes. Among chemical CaP coating processes, biomimetic processes feature pseudo-physiological coating conditions using supersaturated CaP solutions. Due to such pseudo-physiological conditions, various biofunctional substances including proteins, antibiotics, nucleic acids, antibodies, and lipids can be incorporated within CaP layers via coprecipitation while retaining their biological activity. ${ }^{25,45-47}$ In addition, biomimetic processes can be applied even to thermally undurable substrates, including biodegradable polymers.

A conventional biomimetic process is generally carried out in a sequence of steps that include the surface modification of a substrate and the immersion of the surface-modified substrate in a supersaturated $\mathrm{CaP}$ solution such as a simulated body fluid (SBF). ${ }^{48,49}$ In the surface-modification step, the surface of a substrate is modified with hydrophilic functional groups (e.g., $\mathrm{Si}-\mathrm{OH}, \mathrm{Ti}-\mathrm{OH}, \mathrm{COOH}$, and $\mathrm{SO}_{3} \mathrm{H}$ ) and/or $\mathrm{CaP}$ seeds. In the subsequent immersion step, the surface-modified substrate is immersed in a supersaturated CaP solution to grow a CaP layer on the surface. When certain biofunctional substances are added to the supersaturated CaP solution at appropriate concentrations, they are spontaneously incorporated into the CaP layer via coprecipitation, providing various biological functions. ${ }^{25,45-47}$

A critical disadvantage of conventional biomimetic processes is their impracticality; they are usually time-consuming (hours to days) due to the multiple steps, including a complicated surfacemodification step, and the relatively low growth rate of CaP. To overcome this disadvantage, physical stimulation (e.g., laser irradiation, ${ }^{50-54}$ ultraviolet (UV) irradiation, ${ }^{55,56}$ and microwave irradiation $^{57-60}$ ) has been introduced into biomimetic processes. In this review, we focus on the laser irradiation, specifically, laser processing in a supersaturated CaP solution. This process combines a physical laser process and a chemical precipitation process in a single step, which enables rapid and area-specific $\mathrm{CaP}$ precipitation at the laser-irradiated solid-liquid interface (i.e., the interface between a substrate and a metastable supersaturated CaP solution). Laser stimulation was initially applied as a CaP-precoating method before the immersion step in supersaturated CaP solution. ${ }^{50-54}$ Such two-step CaP coating techniques are described in Section 2.2. Recently, these twostep techniques have been refined, and one-step CaP coating was achieved using a laser-assisted biomimetic (LAB) process; ${ }^{38-42}$ this process is described in detail in Section 2.3.

\subsection{Laser-assisted two-step CaP coating techniques}

2.2.1 Focused laser processing in supersaturated solutions. A laser-liquid-solid interaction (LLSI) process was reported in 2004 by Pramatarova et al. as a CaP precoating technique that utilizes laser processing in supersaturated CaP solutions. ${ }^{50-53}$ In this process, a focused pulsed laser light is irradiated with scanning on a substrate immersed in SBF. SBF is a metastable supersaturated $\mathrm{CaP}$ solution with a temperature and ion concentrations that are approximately equal to those of human blood plasma. ${ }^{48}$ Focused laser irradiation in SBF resulted in in situ CaP precipitation (CaP precoating) on the substrate surface. The laser-irradiated substrate was then immersed in another SBF for up to $24 \mathrm{~h}$ at $37{ }^{\circ} \mathrm{C}$ without laser irradiation to allow CaP growth. This two-step CaP coating technique (the LLSI process followed by SBF immersion) was applied to several substrates such as metallic and ceramic, but not to organic polymers. This might be because the reported LLSI process employs a focused laser light with a relatively high fluence of $\sim 3 \mathrm{~kJ}$ per pulse per $\mathrm{cm}^{2}$.

2.2.2 Unfocused laser processing in supersaturated solutions. In 2009, Lee et al. employed much weaker pulsed laser light to prepare a CaP coating on a polymeric substrate using a similar two-step technique. ${ }^{54}$ In the first step, unfocused pulsed UV $\left(\lambda=355 \mathrm{~nm}\right.$ ) laser light (64 mJ per pulse per $\mathrm{cm}^{2}, 10 \mathrm{~Hz}$ ) was irradiated without scanning on the surface of an ethylene-vinyl alcohol copolymer (EVOH) substrate immersed in a supersaturated $\mathrm{CaP}$ solution. As a supersaturated $\mathrm{CaP}$ solution, they used a so-called CP solution ( $\mathrm{NaCl} 142 \mathrm{mM}, \mathrm{K}_{2} \mathrm{HPO}_{4} \cdot 3 \mathrm{H}_{2} \mathrm{O} 1.50 \mathrm{mM}$, $\mathrm{CaCl}_{2} 3.75 \mathrm{mM}$, buffered to $\mathrm{pH}=7.40$ at $\left.25{ }^{\circ} \mathrm{C}^{61}\right)$. This $\mathrm{CP}$ solution has $\mathrm{Ca}$ and $\mathrm{P}$ concentrations of 1.5 times those of SBF and contains no unnecessary ions (magnesium, sulfate, and carbonate ions). After pulsed laser irradiation for $3 \mathrm{~h}$ in the $\mathrm{CP}$ solution (Fig. 2a, left), CaP was precoated on the irradiated surface ( $5 \mathrm{~mm}$ diameter circle) of the EVOH substrate. In the second step, the laser-irradiated substrate was immersed in the CP solution without laser irradiation for $24 \mathrm{~h}$ (Fig. 2a, right), resulting in the formation of a continuous micro-thin layer of CaP. According to X-ray diffraction analysis, the CaP phase in the layer was low-crystalline HAp. The CaP layer was formed only on the irradiated area of the EVOH surface and not on the non-irradiated area (Fig. 2b), indicating that the first laser irradiation was an essential step for the formation of CaP.

\subsection{Laser-assisted one-step CaP coating technique: LAB process}

2.3.1 CaP coating on EVOH substrate. In the two-step techniques described in Section 2.2, the overall processing time including the immersion period in the second step is longer than $24 \mathrm{~h}$. Recently, we developed a rapid (<30 $\mathrm{min}$ ) and onestep CaP coating technique for the EVOH substrates by 
(a)

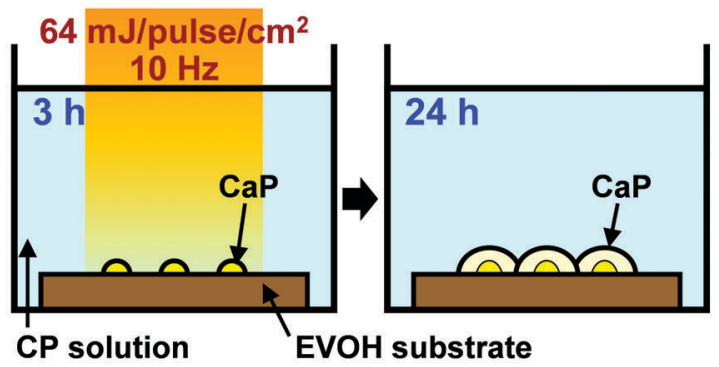

(b)

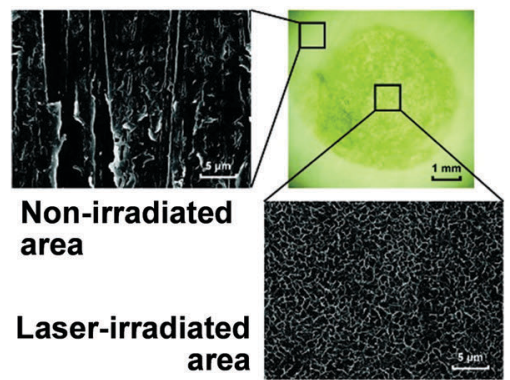

Fig. 2 Laser-assisted two-step biomimetic process using the EVOH substrate. (a) Schematic illustration. (b) Optical microscopy (upper right) and scanning electron microscopy (SEM) images of the laser-irradiated (lower right) and non-irradiated (upper left) surfaces of the EVOH substrate after laser irradiation for $3 \mathrm{~h}$ and subsequent immersion in CP solution for $24 \mathrm{~h}$ (modified from ref. 54 with permission).

(a)

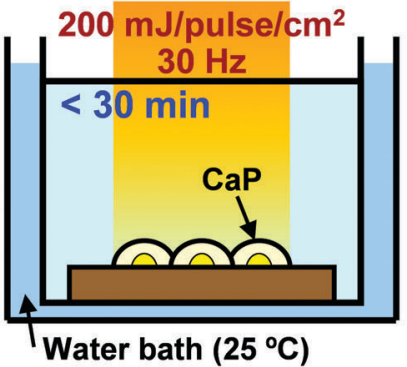

(b)

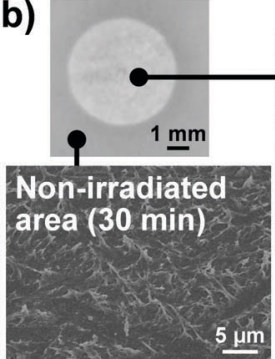

Laser-irradiated area
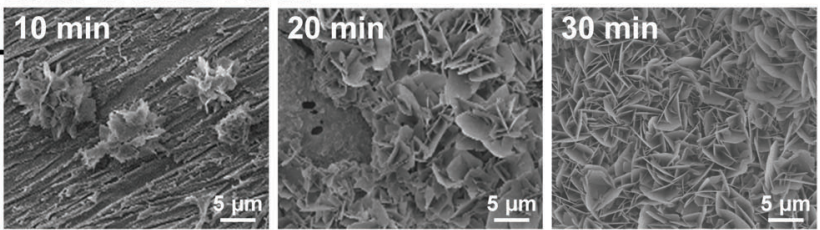

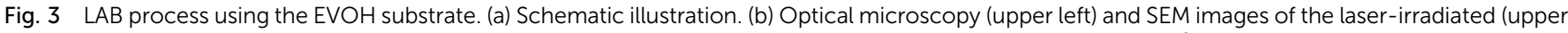

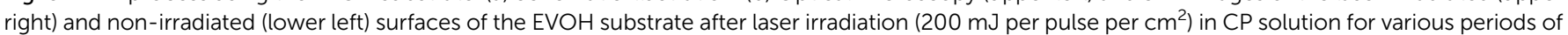
time $(10,20$, and $30 \mathrm{~min})$ (modified from ref. 38 with permission).

simplifying Lee's two-step process. ${ }^{38}$ In this new process (referred to as a laser-assisted biomimetic (LAB) process), unfocused pulsed UV $(\lambda=355 \mathrm{~nm})$ laser light with a slightly higher fluence $\left(200 \mathrm{~mJ}\right.$ per pulse per $\left.\mathrm{cm}^{2}\right)$ and frequency $(30 \mathrm{~Hz})$ than those used in Lee's process was used to irradiate the EVOH substrate immersed in the CP solution maintained at $25{ }^{\circ} \mathrm{C}$ by a water bath (Fig. 3a). Within only $10 \mathrm{~min}$ of irradiation, CaP began to precipitate on the laser-irradiated EVOH surface (5 mm diameter circle) (Fig. 3b). After irradiation for $30 \mathrm{~min}$, a continuous CaP layer with a plate-like structure fully covered the laser-irradiated surface (Fig. 3b). Note that the metastable CP solution remained clear, indicating that homogeneous nucleation was not induced during the LAB process. Therefore, CaP precipitated not through the sedimentation of homogeneously nucleated CaP particles but through the lightmaterial interactions at the laser-irradiated EVOH surface. The crystalline phase of the CaP layer was mainly OCP and a small amount of HAp. Like the previous two-step techniques, the LAB process was also capable of generating an area-specific $\mathrm{CaP}$ coating on the laser-irradiated surface (Fig. 3b).

Our CaP coating technique using the LAB process is carried out rapidly in one step without a prior surface-modification step or a post-immersion step in supersaturated CaP solution. These characteristics represent advantages over the conventional two-step biomimetic CaP coating techniques.

2.3.2 Mechanism behind CaP precipitation in the LAB process. In the LAB process, $\mathrm{CaP}$ most likely precipitates due to the combined effects of laser surface modification and selective heating at the laser-irradiated solid-liquid interface (Fig. 4). To verify these effects, we performed two control experiments using the EVOH substrate. ${ }^{38}$

First, we performed the same UV laser irradiation but without a temperature-controlled water bath to amplify the heating effect on the EVOH substrate. As shown in Fig. 5a, the temperature of the $\mathrm{CP}$ solution increased from its original temperature $\left(25{ }^{\circ} \mathrm{C}\right)$ with increasing irradiation time of the EVOH substrate. In the absence of the substrate, the temperature increase of the same solution was negligible (Fig. 5a) because the CP solution absorbs very little light at $355 \mathrm{~nm}$. Therefore, the increased temperature in the presence of the

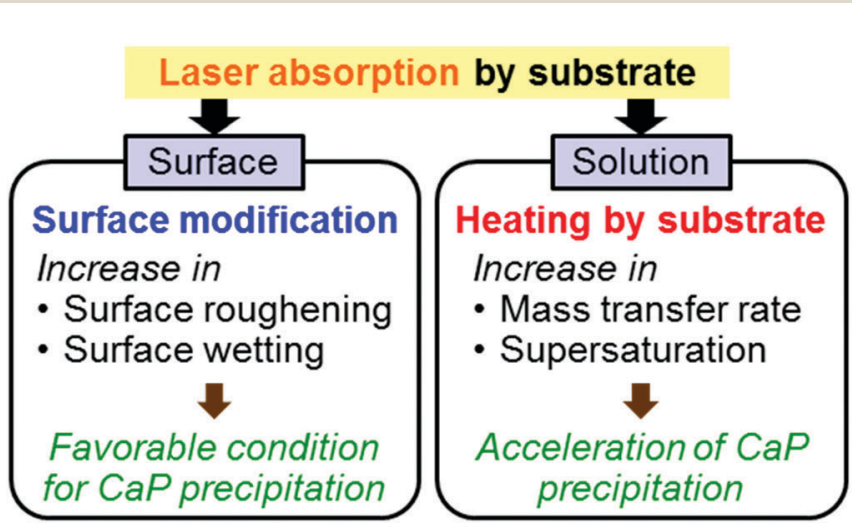

Fig. 4 Putative mechanism of CaP precipitation on the EVOH substrate using the LAB process. 
(a)

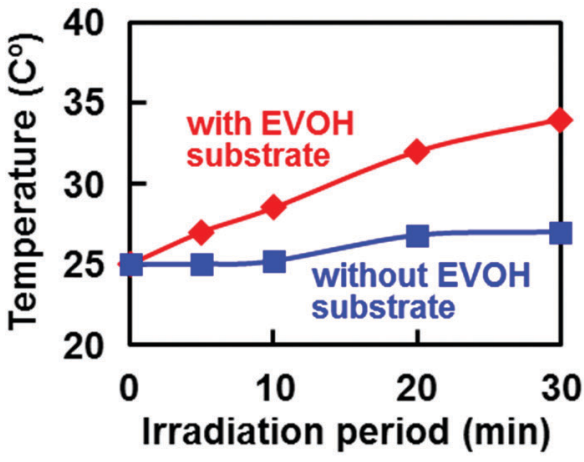

(b)

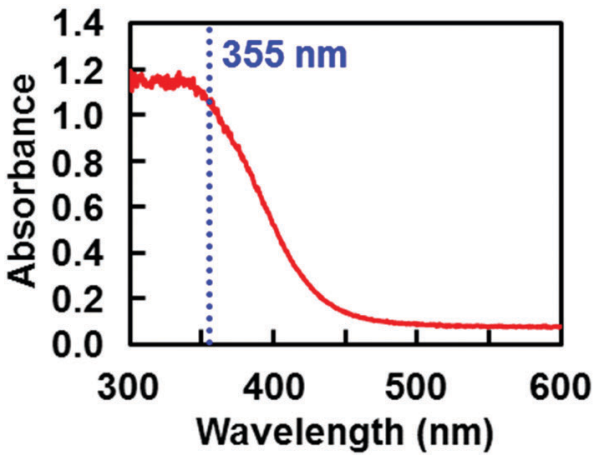

Fig. 5 (a) Change in temperature of the CP solution without a temperature-controlled water bath during laser irradiation $(200 \mathrm{~mJ}$ per pulse per $\mathrm{cm}^{2}$ ) with and without the EVOH substrate (modified from ref. 38 with permission). (b) Absorption spectrum of the EVOH substrate (modified from ref. 40 with permission).

EVOH substrate must be due to laser absorption by the substrate and the resulting selective heating via light-to-heat energy conversion at the surface. In fact, the EVOH substrate showed good light absorption at $355 \mathrm{~nm}$ (Fig. 5b). Even under the temperature control of the water bath (the normal conditions of the $\mathrm{LAB}$ process), the irradiated surface should be selectively heated to locally increase the temperature of the surrounding CP solution. This increase in temperature in the CP solution should have an accelerating effect on CaP nucleation and growth by increasing both the mass transfer rate and the degree of supersaturation of the solution with respect to CaPs (Fig. 4). Note that CaPs including HAp and OCP have lower solubilities at higher temperatures compared to at $25{ }^{\circ} \mathrm{C}$, different from many other inorganic crystals. ${ }^{62,63}$

Second, laser irradiation was performed in ultrapure water to examine the structural changes in the surface of the base $\mathrm{EVOH}$ substrate. As shown in the SEM images in Fig. 6a, submicrometersize pores formed on the EVOH surface after laser irradiation in ultrapure water. As the irradiation period in ultrapure water increased, the contact angle of water on the EVOH surface decreased (Fig. 6b). Similar surface reactions including surface roughening and wetting are expected to occur in the CP solution (normal conditions of the LAB process). The resulting submicroporous surface with increased wettability should provide a favorable environment for CaP precipitation in the CP solution.

As a result of the laser-induced surface modification and the selective heating described above, a CaP layer was formed (a)

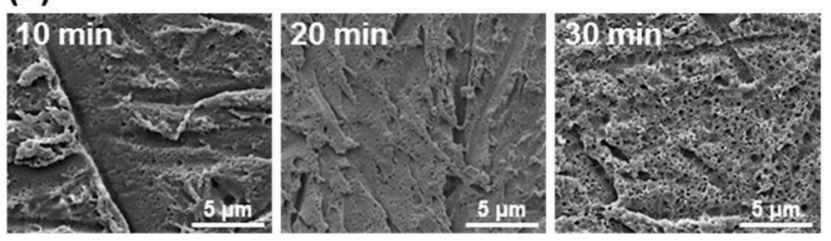

(b)

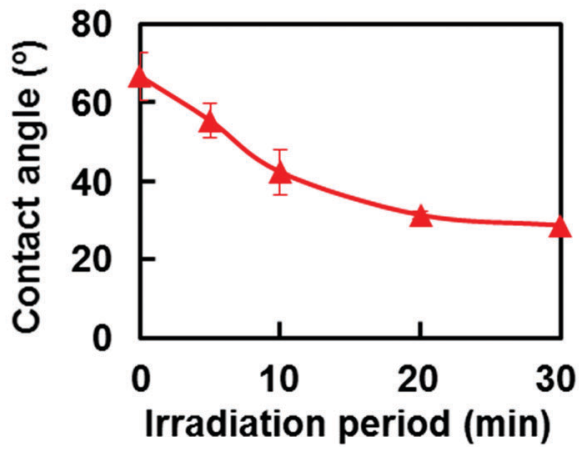

Fig. 6 (a) SEM images of the laser-irradiated surfaces of the EVOH substrates after UV laser irradiation (200 $\mathrm{mJ}$ per pulse per $\mathrm{cm}^{2}$ ) in ultrapure water for various periods of time $(10,20$, and $30 \mathrm{~min})$. (b) Changes in the contact angle of water on the laser-irradiated surface of the EVOH substrate during UV laser irradiation (200 $\mathrm{mJ}$ per pulse per $\mathrm{cm}^{2}$ ) in ultrapure water (average \pm standard deviation) (modified from ref. 38 with permission).

specifically at the laser-irradiated solid-liquid interface on the EVOH substrate (Fig. 4).

2.3.3 Application of the LAB process to other substrates. Our CaP coating technique using the LAB process is applicable to not only $\mathrm{EVOH}$, but other polymeric, ceramic, and metallic substrates that can absorb sufficient laser light energy. ${ }^{39-42}$ However, it is not applicable to substrates with insufficient laser absorption because laser absorption by a substrate is a prerequisite for $\mathrm{CaP}$ precipitation in the $\mathrm{LAB}$ process, as verified in the preceding section.

We have tested four substrates in addition to EVOH: polyethylene terephthalate (PET, polymer), polyethylene (PE, polymer), sintered HAp (sHAp, ceramic), and titanium (Ti, metal). After the LAB process using UV laser $(\lambda=355 \mathrm{~nm})$, CaP layers were formed on the PET, ${ }^{40}$ SHAp $^{39}$ and Ti substrates ${ }^{41,42}$ (Fig. 7), but not on the PE substrate. ${ }^{40}$ These results correlated well with the light absorption ability of the substrate at the employed laser wavelength $(355 \mathrm{~nm})$ and with the temperature change of the CP solution during laser irradiation of the substrate without a
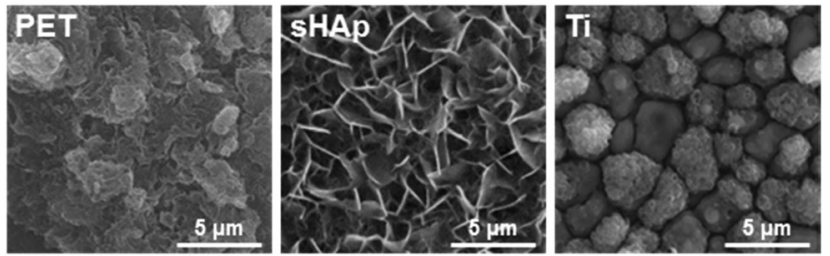

Fig. 7 SEM images of the laser-irradiated surfaces of the PET, sHAp, and Ti substrates after the LAB process ( $133 \mathrm{~mJ}$ per pulse per $\mathrm{cm}^{2}, 30 \mathrm{~min}$ ) (modified from ref. 39-41 with permission). 
temperature-controlled water bath. For example, the PE substrate exhibited little light absorption at $355 \mathrm{~nm}$ and negligible heating of the CP solution under irradiation, thereby inducing no CaP precipitation during the LAB process. ${ }^{40}$ Conversely, other substrates including the EVOH substrate (Fig. 5b) showed higher light absorption at $355 \mathrm{~nm}$ than the PE substrate, resulting in a significant temperature increase of the $\mathrm{CP}$ solution under irradiation. Consequently, CaP precipitated on the EVOH, PET, sHAp, and Ti substrates by the LAB process using UV laser $(\lambda=355 \mathrm{~nm})$ (Fig. $3 \mathrm{~b}$ and 7$)$.

The mechanism underlying CaP precipitation in the LAB process should depend on the type of substrate due to the different light absorption abilities and surface chemistries of different substrates. The mechanism of CaP precipitation on the PET substrate is likely to be similar to that proposed for EVOH, which involves laser-induced surface modification (microdeformation and wetting) and selective heating at the surface (Fig. 4). Our numerical estimates showed that the increases in surface temperatures of the EVOH and PET substrates by one pulse irradiation were just several degrees. ${ }^{40}$ Thus, nonthermal photochemical reactions might be involved in the laser-induced surface modification of these polymeric substrates in the LAB process. On the other hand, we estimated that the surface of the Ti substrate was heated up to several thousand degrees during one pulse irradiation during the LAB process. ${ }^{42}$ Therefore, the laser-induced surface modification of the Ti substrate should involve high-temperature processes such as melting, vaporization, ionization, and oxidization. In fact, the Ti surface was deformed and oxidized into the high-temperature phase (rutile) of titanium dioxide following laser irradiation. In the case of the ceramic sHAp substrate, which contains intrinsic CaP nucleation sites on its surface, CaP can precipitate on the sHAp surface in the supersaturated CP solution, even without any surface deformation. ${ }^{39}$ Laser irradiation simply accelerates CaP precipitation on the sHAp substrate through selective surface heating in the CP solution; laser irradiation does not affect the morphology of the sHAp surface under SEM observation. Due to such differences in CaP precipitation mechanism, the surface morphologies and crystalline phases of the $\mathrm{CaP}$ layers varied with substrate, even under the same irradiation conditions (laser fluence and irradiation time) (Fig. 7).

2.3.4 Effect of laser fluence and wavelength on CaP precipitation. Laser fluence has a significant effect on $\mathrm{CaP}$ precipitation in the $\mathrm{LAB}$ process. CaP precipitation is promoted to a certain extent by an increase in fluence due to fluence-dependent surface modification and/or heating. ${ }^{38,39,42}$ However, the use of a higher fluence does not always promote $\mathrm{CaP}$ precipitation, as revealed by the surface composition ( $\mathrm{Ca} / \mathrm{Ti}$ ratio) of the Ti substrate after the $\mathrm{LAB}$ process with different wavelengths and fluences (Fig. 8). This is because excessive fluence causes destructive surface reactions. ${ }^{42}$ Thus, there exists an optimal range of fluence for each substrate and each irradiation system.

As a laser light, UV (355 nm), visible (VIS, $532 \mathrm{~nm}$ ), and nearinfrared (NIR, $1064 \mathrm{~nm}$ ) lights of Nd:YAG laser were effective in inducing $\mathrm{CaP}$ precipitation on the Ti substrate using the LAB process. ${ }^{42}$ This occurred because Ti shows relatively high light absorption at a wide range of wavelengths from UV to NIR, although the light absorption rate depended on the wavelength. The effect of laser heating and consequently the amount (and crystalline structures as well) of the CaP precipitates varied with laser wavelength, even when laser fluence was kept constant (compare $\mathrm{Ca} / \mathrm{Ti}$ ratio of the three substrates treated with the same fluence) (Fig. 8).

In the LAB process, a suitable laser wavelength should be selected according to the optical absorption properties of the intended substrate, and the laser fluence should be tuned to induce efficient $\mathrm{CaP}$ precipitation at the laser-irradiated surface of the substrate.

2.3.5 Biological properties of $\mathrm{CaP}$ layers fabricated by the LAB process. The CaP layers fabricated by the LAB process
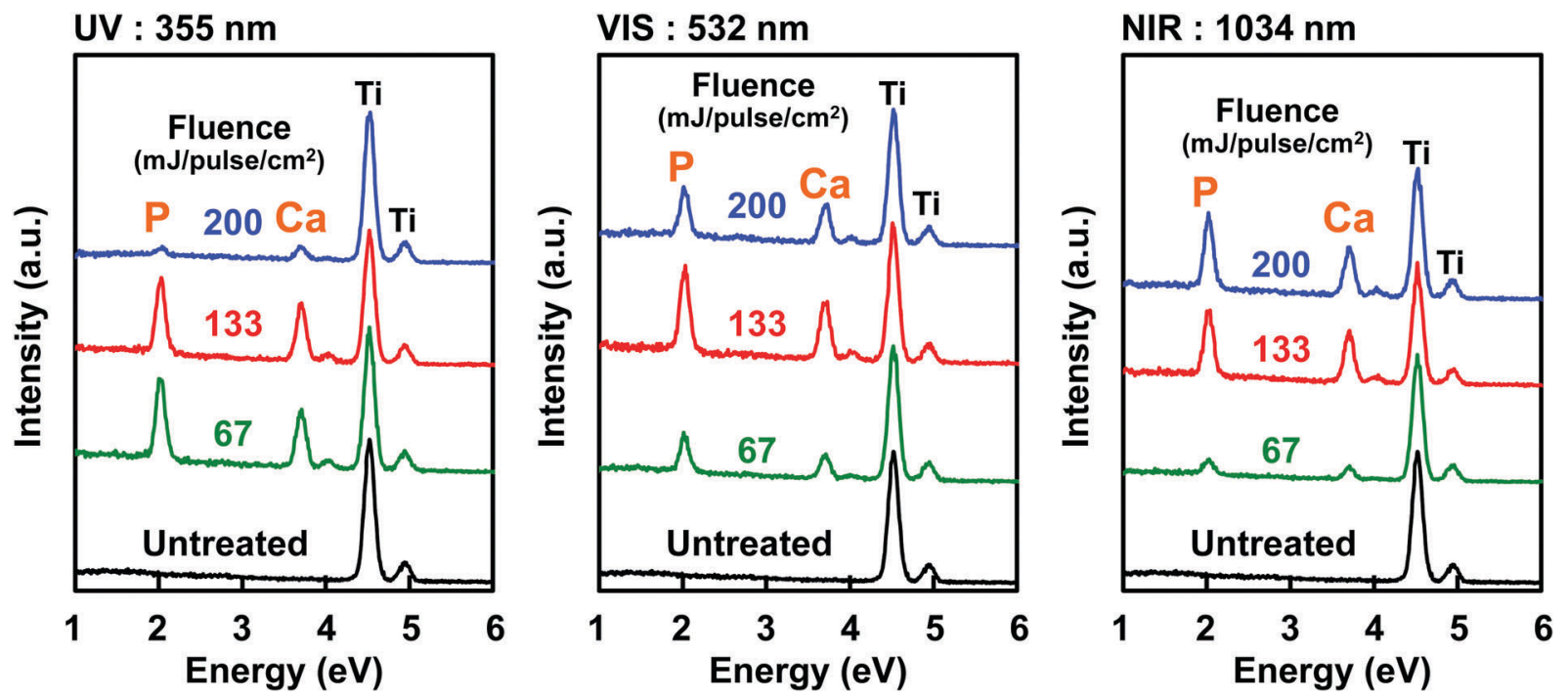

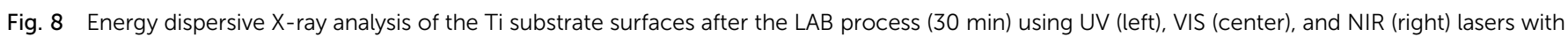
different fluences $\left(67,133\right.$, and $200 \mathrm{~mJ}$ per pulse per $\mathrm{cm}^{2}$ ) (modified from ref. 42 with permission). 
showed good cell compatibility. According to our preliminary cell adhesion study using epithelial-like CHO-K1 and osteoblast-like MG-63 cell lines, the CaP-coated EVOH substrate (Section 2.3.1, laser-irradiated area after the LAB process) showed better cell adhesion properties than the naked EVOH substrate (nonirradiated area) for both cell lines (Fig. 9a). ${ }^{38}$ No adverse effects on cell adhesion were observed in this preliminary study.

In biomimetic processes, biological properties of CaP layers can be further improved or tailored by immobilizing certain biofunctional substances via the coprecipitation of $\mathrm{CaP}$ and biofunctional substances in supersaturated CaP solutions. ${ }^{25,45-47}$ Thus, we attempted to simultaneously immobilize biofunctional substances and precipitate CaP onto Ti substrates using the LAB process. ${ }^{41}$ As the biofunctional substances, we selected zinc, an essential trace element, and fibronectin, a cell-adhesion protein, both of which can act as osteogenic substances and stimulate bone regeneration. ${ }^{64-66}$ We supplemented the CP solution with $\mathrm{ZnCl}_{2}$ or fibronectin at various concentrations and performed the LAB process using $\mathrm{Ti}$ substrates and the modified $\mathrm{CP}$ solutions. After pulsed laser irradiation for $30 \mathrm{~min}$, zinc or the components of fibronectin (molecules and/or their derivatives) along with CaP were present on the Ti surface. The contents of both zinc and the fibronectin components at the Ti surface were controllable by changing their initial concentrations in the
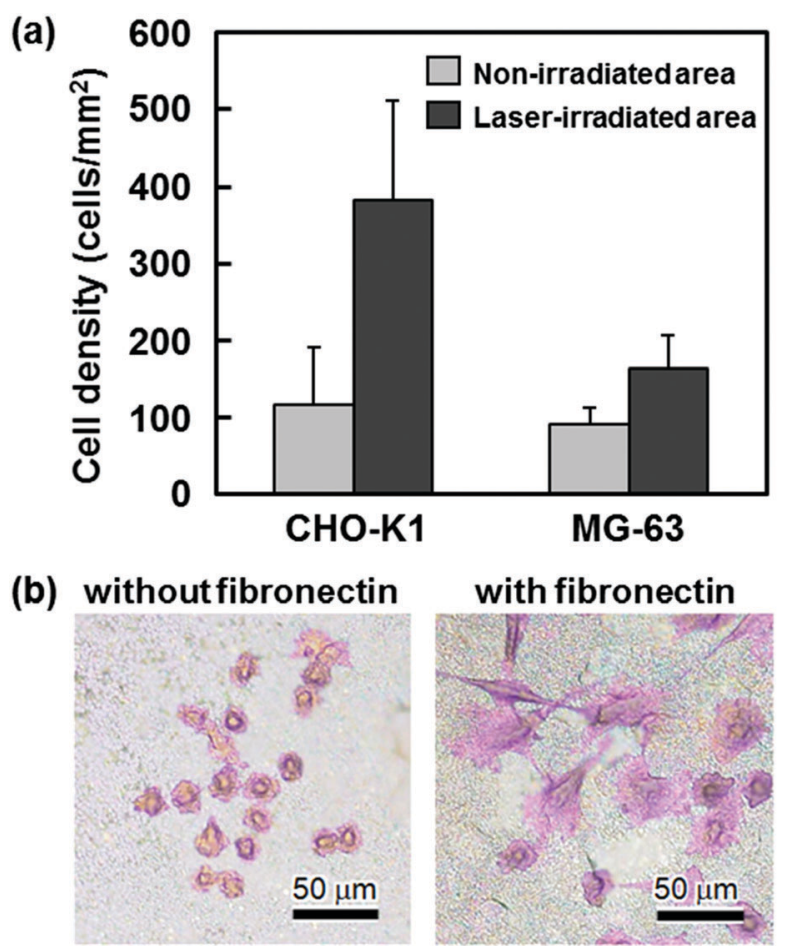

Fig. 9 Preliminary cell adhesion studies. (a) Number densities of $\mathrm{CHO}-\mathrm{K} 1$ and MG-63 cells (after $2 \mathrm{~h}$ of culture) adhering to the laser-irradiated and non-irradiated surfaces of the EVOH substrates after the LAB process (average \pm standard deviation) (modified from ref. 38 with permission). (b) Optical microscopy images of $\mathrm{CHO}-\mathrm{K} 1$ cells (after $24 \mathrm{~h}$ of culture) on the laser-irradiated surfaces of the Ti substrates after the LAB process in the CP solution supplemented with and without fibronectin (modified from ref. 41 with permission). modified CP solution. In the case of zinc, a cationic zinc ion was likely incorporated within the $\mathrm{CaP}$ nanocrystals through partial substitution at the calcium ion sites. In the case of fibronectin macromolecules, the experimental results suggested their partial degradation, aggregation, and/or denaturalization in the CP solution under the tested irradiation conditions. Despite this, the fibronectin components introduced on the Ti surface enhanced cell adhesion and spreading on the CaPcoated Ti substrate (Fig. 9b). ${ }^{41}$ This suggests that the fibronectin components provided active binding sites on the Ti surface, although it remains unclear whether these components were incorporated within the interstices of the CaP nanocrystals or adsorbed onto the precipitated CaP surface. From the perspective of the retention of native fibronectin structures and functions, posterior fibronectin adsorption onto the CaP-coated substrate would also be effective and probably more practical. The immobilization method should be carefully chosen and optimized in consideration of the types of biofunctional substances employed and the intended applications.

\subsection{Challenges and perspective}

As described above, the LAB process is a one-step, laser-assisted biomimetic CaP coating technique that allows the area-specific coating of $\mathrm{CaP}$ on various substrates with laser light absorption. The LAB process is carried out under normal pressures and temperatures in a pseudo-physiological supersaturated CaP solution. Hence, this process can be applied to polymeric substrates with low thermal durability as well as thermally durable metallic and ceramic substrates. Substrates that have been coated with CaPs by the LAB process include PET, SHAp, and $\mathrm{Ti}$, all of which are important biomaterials used in medical and dental applications. Considering that the irradiation area is narrow ( $5 \mathrm{~mm}$ diameter circle) in our current system, the present $\mathrm{LAB}$ process should be suitable for small-sized biomaterials such as dental implants, bone screws, pins, and wires. The irradiation area could be expanded by rearranging the laser equipment, further broadening the application of the LAB process.

Our new CaP coating technique using the LAB process has the potential to provide better clinical treatments. Since clinical treatments with lasers having various characteristics (pulse width, frequency, wavelength, etc.) have become popular in recent years, ${ }^{67-69}$ the $\mathrm{LAB}$ process might be utilized in medical settings for the preoperative or intraoperative surface functionalization of biomaterials. The CaP layers fabricated by the LAB process were composed mainly of OCP and/or HAp, both of which have been shown to exhibit good biocompatibility and osteoconductivity. Thus, our CaP coating technique using the $\mathrm{LAB}$ process has the potential to provide a target region of a biomaterial surface with good biocompatibility and osteoconductivity. Furthermore, biological properties of CaP layers can be further improved or tailored by immobilizing certain biofunctional substances, as demonstrated in Section 2.3.5. This might enable tailored medicine on demand from patients (e.g., zinc-incorporated CaP coating on bone fixation devices for osteoporotic fracture caused by zinc deficiency). These are challenges for future study. 


\section{Physicochemical fabrication of CaP-based nanospheres}

\subsection{Fabrication techniques of CaP-based nanoparticles}

3.1.1 Conventional physical and chemical processes. CaP-based nanoparticles (nanoparticles including CaPs as a matrix) can be fabricated by a variety of physical and chemical processes. ${ }^{4-7}$ Physical processes include plasma spraying, mechanochemical reaction, solid-state reaction, and laser ablation in liquid. Chemical processes include precipitation, hydrothermal, hydrolysis, emulsion, and sol-gel methods. As is the case with CaP layer fabrication processes, each process has advantages and disadvantages.

3.1.2 Precipitation process: from chemical to physicochemical processes. Among conventional fabrication processes of CaP-based nanoparticles, the precipitation process using supersaturated CaP solutions has the advantage of proceeding under mild reaction conditions (low temperature, normal pressure, and neutral $\mathrm{pH}$ ). The precipitation process generally uses highly supersaturated and labile CaP solutions to induce homogeneous CaP nucleation in entire solutions. Like biomimetic CaP coating processes described in Section 2.1.2, various biofunctional substances such as proteins and nucleic acids can be incorporated within $\mathrm{CaP}$ nanoparticles via coprecipitation while retaining their biological activity.

The disadvantage of the precipitation processes is the difficulty in controlling the shapes and sizes of the particles. Therefore, the precipitation process often requires specific surfactants for controlling nanoparticle shape and size ${ }^{70,71}$ which in turn may cause safety issues for biomedical applications. Another approach without the use of surfactants is the application of physical stimulations such as laser irradiation, microwave irradiation, ${ }^{72-74}$ and ultrasonic irradiation. ${ }^{75}$

We have recently developed a surfactant-free, rapid (short irradiation time), and one-pot physicochemical process for fabricating CaP-based nanoparticles by combining a physical laser process with a chemical precipitation process. ${ }^{43,44}$ The resulting particles possess well-regulated spherical structures, which are advantageous for biomedical applications due to their reduced agglomeration, easy redispersion, and minimal physical irritation of cells, tissues, and organs. In the next section (Section 3.2), we introduce related previous studies on laser processing in liquid solvents for the fabrication of inorganic nanospheres (including CaP nanospheres) using solid sources (bulk targets or source nanopowders). In the following section (Section 3.3), we review our physicochemical process via laser processing in labile supersaturated $\mathrm{CaP}$ solutions for the fabrication of $\mathrm{CaP}$ nanospheres using liquid sources (ion solutions).

\subsection{Fabrication of inorganic nanospheres via laser processing in liquid solvents using solid sources}

3.2.1 Laser ablation in liquid process. A laser ablation in liquid process was developed for the fabrication of nanoparticles in 1993. ${ }^{76-79}$ In this process, a focused laser light is irradiated onto a bulk target immersed in a liquid solvent to provide a colloidal solution of nanoparticles. The main formation mechanisms of

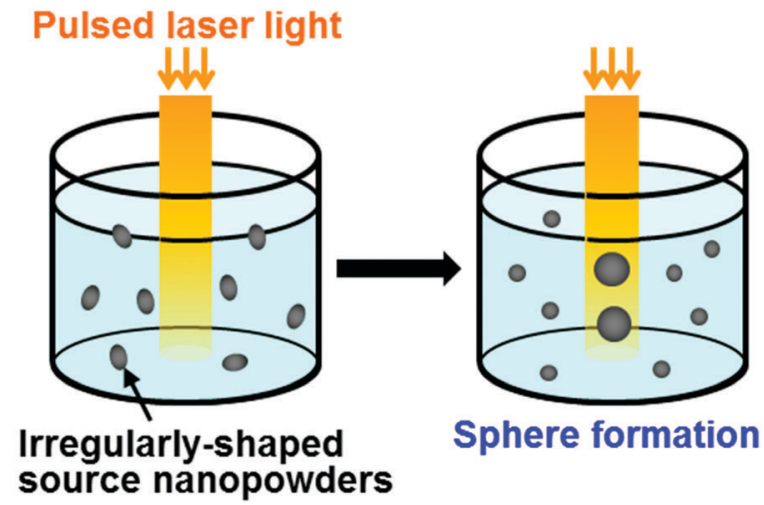

Fig. 10 Schematic illustration of the pulsed laser melting in liquid process.

these nanoparticles are thought to be based on thermal evaporation (i.e., vapor or plasma formation) and/or the explosive ejection of nanodroplets. ${ }^{79}$ To date, various nanoparticles including semiconductors, metals, metal oxides, organic dyes, and diamonds have been fabricated by laser ablation. CaP nanoparticles with diameters of less than $50 \mathrm{~nm}$ have also been fabricated using a CaP bulk target. ${ }^{80-82}$ This laser ablation in liquid process is carried out in a liquid solvent including water without any surfactants. However, mass productivity is relatively low because of the tiny irradiation area of the focused laser beam (e.g., diameter of $120 \mu \mathrm{m}^{81}$ ).

3.2.2 Pulsed laser melting in liquid process. Around 2010, a pulsed laser melting in liquid process was developed for the fabrication of nanospheres (diameters of 100-500 nm) of semiconductors, metals, and metal oxides using an unfocused pulsed laser light. ${ }^{83-88}$ In this process, irregularly shaped source nanopowders are dispersed in a liquid solvent (Fig. 10, left) and irradiated with relatively weak pulsed laser light with wavelength in the UV to NIR range. This induces the spheroidization of source nanopowders on the nanoscale in one step within 10-60 min (Fig. 10, right). During laser irradiation, the source nanopowders selectively absorb laser light and are heated and melted into spherical droplets. The melting droplets are rapidly quenched in the liquid during the interval between laser pulses. Although the pulsed laser melting in liquid process has been used to fabricate various nanospheres, it failed to fabricate CaP nanospheres due to the insufficient laser absorption of CaPs in the UV to NIR wavelength range.

To enhance light-CaP interactions, we integrated HAp nanopowders with carbon nanopowders as a light-absorbing agent by mechanical milling prior to the pulsed laser melting in liquid process (Fig. 11a). ${ }^{89}$ The integration with carbon nanopowders as a light-absorbing agent was proposed in previous reports on the fabrication of nanospheres of optically transparent metal oxides (e.g., $\mathrm{Al}_{2} \mathrm{O}_{3}, \mathrm{MgO}$, and $\mathrm{ZrO}_{2}$ ). ${ }^{90,91}$ The carbonintegrated HAp nanopowders (Fig. 11b, left) were dispersed into ethanol and irradiated with a weak pulsed laser light $(\lambda=355 \mathrm{~nm}$, $8 \mathrm{~mm}$ diameter circle) without focusing. After irradiation for $20 \mathrm{~min}$, CaP nanospheres (Fig. 11b, right) with single-hollow, multi-hollow, and solid structures were obtained (Fig. 11c). During this process, the carbon nanopowders absorbed laser 
light energy and transferred the energy to HAp nanopowders, causing the melting and spheroidization of the carbonintegrated HAp nanopowders in the liquid solvent (ethanol). During laser irradiation, most carbon nanopowders were sublimated or degraded and were not incorporated within the final spheres. The hollows were considered to be produced when the gases produced in the nanopowders were not released before final solidification. The resulting hollow spheres would be advantageous for drug delivery applications due to their large loading capacity.

In the carbon-assisted pulsed laser melting in liquid process, it is possible to incorporate additional functional ions into the nanospheres via ion adsorption onto the spheres followed by melt diffusion under irradiation. We produced $\mathrm{CaP}$ nanospheres with fluorescence by adding terbium ions to the dispersed solution of carbon-integrated HAp nanopowders prior to the pulsed laser melting in liquid process. ${ }^{89} \mathrm{~A}$ larger amount of terbium ions were incorporated into $\mathrm{CaP}$ nanospheres under laser irradiation than under mere stirring without irradiation due to the laser-mediated melt diffusion of terbium ions. The resulting terbium-incorporated CaP nanospheres exhibited fluorescence peaks characteristic of terbium ions (Fig. 11d). The fluorescent hollow nanospheres of terbiumincorporated $\mathrm{CaP}$ would be useful as multifunctional drug delivery carriers with large drug-loading capacity, good biocompatibility, $\mathrm{pH}$-dependent biodegradability, and fluorescent imaging ability.

As described above, pulsed laser melting in liquid process is useful for fabricating various functional nanospheres. Due to the relatively large beam size of unfocused pulsed laser light, the mass productivity of this process was greatly improved compared with the conventional laser ablation in liquid process using focused laser light. However, for the nanosphere fabrication of low-laser-absorbing materials such as CaPs, a prior integration step (mechanical milling) with light-absorbing agents (e.g., carbon nanopowders) was required. In addition, size-regulated CaP nanopowders and carbon nanopowders must be prepared or purchased separately; these nanomaterials in the powder form are generally difficult to handle, and their production cost is relatively high. Rather than powder-powder physical integration, chemical coprecipitation in a labile supersaturated CaP solution would be a much easier way to integrate light-absorbing agents with CaPs. In the following sections, we review our new physicochemical technique for the fabrication of CaP-based spheres using liquid (ion) sources instead of nanopowders, which is based on laser processing in labile supersaturated CaP solutions.

\subsection{Fabrication of CaP nanospheres via laser processing in labile supersaturated CaP solutions}

3.3.1 Fabrication of iron-incorporated CaP nanospheres. We recently proposed a novel physicochemical technique for fabricating CaP-based nanospheres by combining a pulsed laser melting in liquid process (Section 3.2.2) with a chemical coprecipitation process (Section 3.1.2). ${ }^{43,44}$ We hypothesized that nanoprecipitates with the ability to absorb laser light (a)

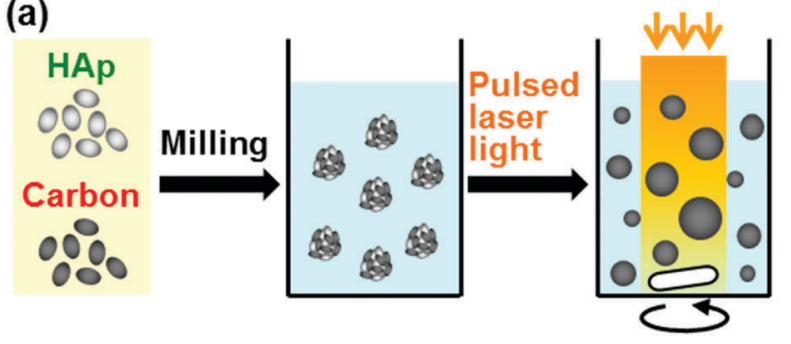

(b) Carbon-integrated HAp nanopowders
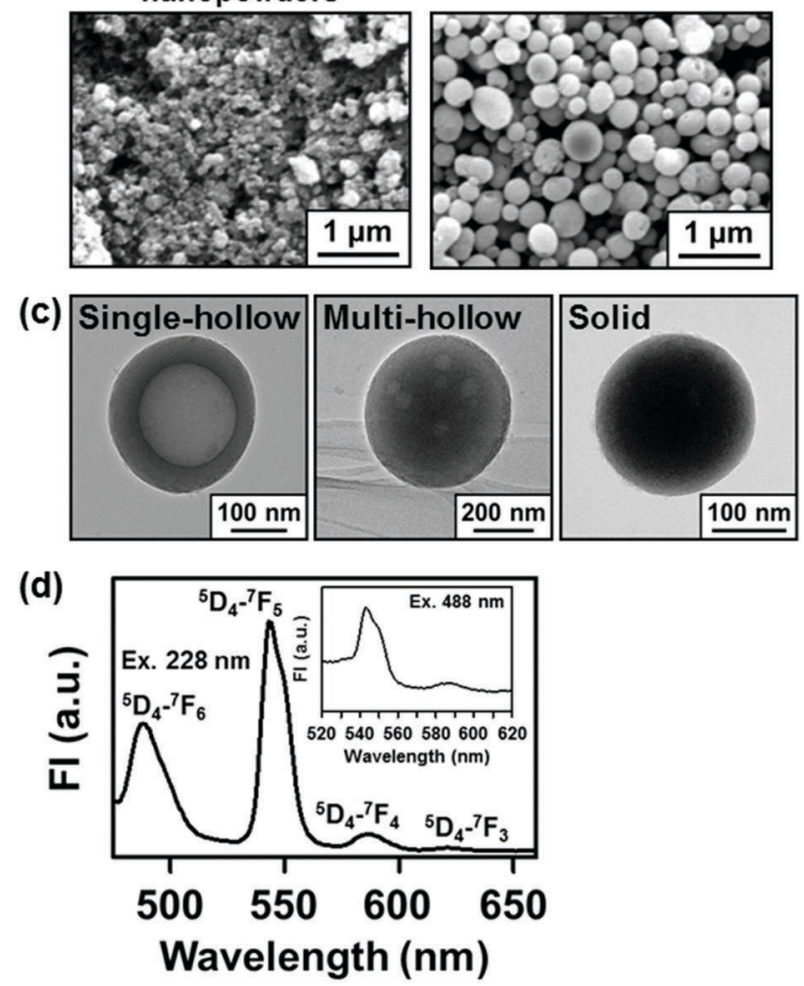

Fig. 11 Fabrication of CaP nanospheres by the pulsed laser melting in liquid process (modified from ref. 89 with permission). (a) Schematic illustration. (b) SEM images of the carbon-integrated HAp nanopowders and the CaP nanospheres. (c) TEM images of the CaP nanospheres. (d) Fluorescence spectrum of the terbium-incorporated $\mathrm{CaP}$ nanospheres dispersed in ultrapure water with excitation at $228 \mathrm{~nm}$ and $488 \mathrm{~nm}$ (inset).

should form in labile supersaturated CaP solutions supplemented with light-absorbing agents via coprecipitation, and the resulting nanoprecipitates should undergo pulsed laser melting in liquid (Fig. 12a). For this purpose, we prepared a labile supersaturated $\mathrm{CaP}$ solution $(4 \mathrm{~mL}$ in total) supplemented with ferric $\left(\mathrm{Fe}^{3+}\right)$ or ferrous $\left(\mathrm{Fe}^{2+}\right)$ ions as a light-absorbing agent. ${ }^{43,44}$ Upon mixing three ion source solutions: calcium (16.7 mM), phosphate (10.0 $\mathrm{mM})$, and ferric/ferrous ion solutions $(5.0 \mathrm{mM})$, the iron-incorporated CaP nanoprecipitates with light absorption at $355 \mathrm{~nm}$ formed spontaneously through coprecipitation (Fig. 12b). This CaP solution with dispersed nanoprecipitates was irradiated with a weak UV $(\lambda=355 \mathrm{~nm}$, $8 \mathrm{~mm}$ diameter circle) pulsed laser at a fluence of $200 \mathrm{~mJ}$ per pulse per $\mathrm{cm}^{2}$ without focusing. After irradiation for 20-30 min, nanospheres and microspheres of iron-incorporated $\mathrm{CaP}$ with 
(a)

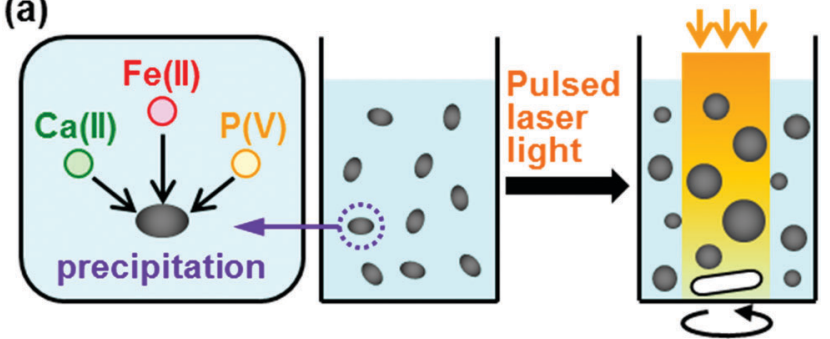

(b)
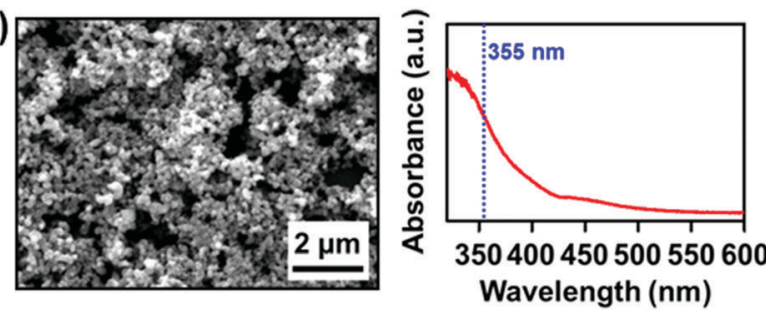

(c)
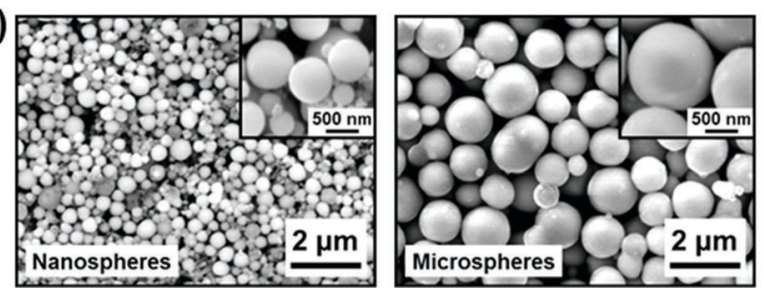

Fig. 12 Physicochemical fabrication of iron-incorporated CaP nanospheres and microspheres using ferrous ions as a light-absorbing agent (modified from ref. 44 with permission). (a) Schematic illustration. (b) SEM image and absorption spectrum of the iron-incorporated CaP nanoprecipitates formed by mixing three ion source solutions prior to laser irradiation. (c) SEM images and magnified SEM images (insets) of the ironincorporated $\mathrm{CaP}$ nanospheres and microspheres.

amorphous structures were obtained (Fig. 12c). It is considered that the iron-incorporated nanoprecipitates absorbed sufficient laser light energy for melting and spheroidization via ironenhanced light-material interaction. The thus-formed nanospheres grew with irradiation time by fusing together and incorporating calcium, phosphate, ferric/ferrous ions, and their clusters in the supersaturated solution. The nucleationgrowth process and Ostwald ripening under supersaturated conditions might have been involved in the sphere growth, which is different from the growth process (fusion of source nanopowders) during the conventional pulsed laser melting in liquid process (Section 3.2.2).

The laser irradiation conditions (laser fluence, irradiation time, and wavelength) and the ferric/ferrous ion concentrations in the CaP solution had a critical influence on sphere formation and size (Table 1) along with sphere yield and chemical composition. For example, sphere formation and growth were enhanced with increasing laser fluence from $67 \mathrm{~mJ}$ per pulse per $\mathrm{cm}^{2}$ (no sphere formation) to $133 \mathrm{~mJ}$ per pulse per $\mathrm{cm}^{2}$ (nanosphere formation) and $200 \mathrm{~mJ}$ per pulse per $\mathrm{cm}^{2}$ (both nanosphere and microsphere formation) for the same irradiation time (30 $\mathrm{min})$ and ferric/ferrous ion concentrations $(5.0 \mathrm{mM})$ (Table 1a). Under laser irradiation at $200 \mathrm{~mJ}$ per pulse per $\mathrm{cm}^{2}$, CaPbased nanospheres appeared within $10 \mathrm{~min}$ and grew into microspheres within 15-20 min (Table 1b). As shown in
Table 1 Effect of experimental conditions on sphere formation and size (modified from ref. 43 and 44 with permission). Sphere formation was determined by SEM observation (I: spheres were scarcely observed, and the majority consisted of irregularly shaped precipitates; $\mathrm{N}$ and $\mathrm{M}$ : nanospheres and microspheres without irregularly shaped precipitates were observed, respectively)

(a) Effect of laser fluence (30 min, $\mathrm{Fe}^{3+}$ or $\left.\mathrm{Fe}^{2+}: 5 \mathrm{mM}\right)$

\begin{tabular}{llll}
\hline$\left(\mathrm{mJ}\right.$ per pulse per $\left.\mathrm{cm}^{2}\right)$ & 67 & 133 & 200 \\
\hline $\mathrm{Fe}^{3+}$ & $\mathrm{I}$ & $\mathrm{N}$ & $\mathrm{N}+\mathrm{M}$ \\
$\mathrm{Fe}^{2+}$ & $\mathrm{I}$ & $\mathrm{N}$ & $\mathrm{N}+\mathrm{M}$
\end{tabular}

(b) Effect of irradiation time (200 mJ per pulse per $\mathrm{cm}^{2}, \mathrm{Fe}^{3+}$ or $\left.\mathrm{Fe}^{2+}: 5 \mathrm{mM}\right)$

\begin{tabular}{lllllll}
\hline$(\min )$ & 0 & 5 & 10 & 15 & 20 & 30 \\
\hline $\mathrm{Fe}^{3+}$ & $\mathrm{I}$ & $\mathrm{I}$ & $\mathrm{N}$ & $\mathrm{N}$ & $\mathrm{N}+\mathrm{M}$ & $\mathrm{N}+\mathrm{M}$ \\
$\mathrm{Fe}^{2+}$ & $\mathrm{I}$ & $\mathrm{I}$ & $\mathrm{N}$ & $\mathrm{N}+\mathrm{M}$ & $\mathrm{N}+\mathrm{M}$ & $\mathrm{N}+\mathrm{M}$ \\
\hline
\end{tabular}

(c) Effect of ferric/ferrous ion concentrations (200 mJ per pulse per $\mathrm{cm}^{2}$, $30 \mathrm{~min})$

\begin{tabular}{llllllll}
\hline$(\mathrm{mM})$ & 0 & 1.0 & 2.0 & 5.0 & 7.0 & 10.0 & 20.0 \\
\hline $\mathrm{Fe}^{3+}$ & $\mathrm{I}$ & $\mathrm{I}$ & $\mathrm{N}$ & $\mathrm{N}+\mathrm{M}$ & $\mathrm{N}$ & $\mathrm{I}$ & $\overline{-}^{a}$ \\
$\mathrm{Fe}^{2+}$ & $\mathrm{I}$ & $\mathrm{I}$ & $\mathrm{N}$ & $\mathrm{N}+\mathrm{M}$ & $-^{a}$ & $\mathrm{~N}+\mathrm{M}$ & $\mathrm{N}+\mathrm{M}$
\end{tabular}

${ }^{a}$ Data not obtained.

Table 1c, at least $2.0 \mathrm{mM}$ ferric or ferrous ions were necessary for nanosphere formation under laser irradiation at $200 \mathrm{~mJ}$ per pulse per $\mathrm{cm}^{2}$ for $30 \mathrm{~min}$. In the process using ferric ions, sphere formation and growth were enhanced most at the ferric ion concentration of $5.0 \mathrm{mM}$ (both nanosphere and microsphere were formed). At higher ferric ion concentration, sphere formation was inhibited; only nanospheres (no microspheres) were obtained at $7.0 \mathrm{mM}$, and spheres were scarcely obtained at $10.0 \mathrm{mM}$. This might be due to the acidic property of the ferric ion source, $\mathrm{FeCl}_{3}$, which lowers the solution $\mathrm{pH}$ and is thus unfavorable for CaP nucleation and growth..$^{92}$ In contrast, in the process using ferrous ions, both nanospheres and microspheres were obtained in a wider range of ferrous ion concentrations $(5.0,10.0$, and $20.0 \mathrm{mM})$ because the ferrous ion source, $\mathrm{FeCl}_{2}$, has less of an acidifying effect than $\mathrm{FeCl}_{3}$. It should be noted that the iron content in the spheres increased with increasing ferric/ferrous ion concentrations in the CaP solution. These results suggest that the sizes and chemical compositions of the spheres are controllable by tuning the experimental conditions. The amounts of the spheres obtained by the process using ferric and ferrous ions $(5 \mathrm{mM})$ are estimated to be around 0.6 and $1.4 \mathrm{mg}$, respectively, per batch ( $4 \mathrm{~mL}$ reaction mixture), considering the contents of calcium, phosphorus, and iron in the spheres. ${ }^{44}$

3.3.2 Fabrication of CaP nanospheres containing magnetite nanoparticles. As described in Section 3.3.1, using ferric and ferrous ions as light-absorbing agents, we fabricated iron-incorporated $\mathrm{CaP}$ spheres. The fabricated spheres possessed amorphous structures and did not contain any crystalline magnetite phases. We aimed to coprecipitate magnetite nanoparticles in the CaP-based nanospheres to add magnetic properties towards possible applications in magnetic targeting, imaging, and hyperthermia. ${ }^{93-95}$ In general, magnetite nanoparticles are formed when ferrous 
(a)
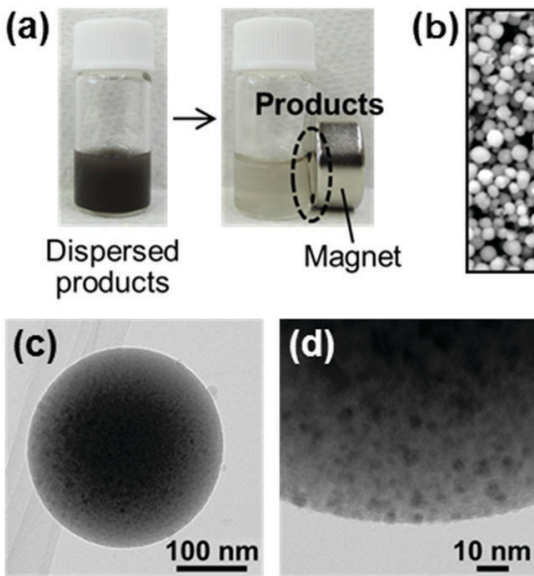

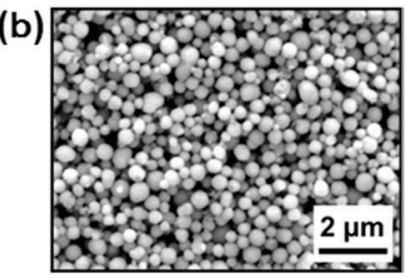

(e)

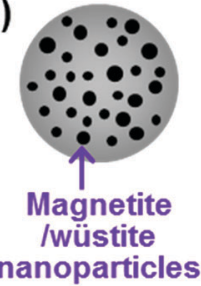

Fig. 13 CaP-based magnetic nanospheres (modified from ref. 44 with permission). (a) Digital images of the magnetic products dispersed in ultrapure water. (b-e) SEM (b), TEM (c), magnified TEM (d), and illustrated (e) images of the spheres.

and ferric ions coexists in a basic solution. We supposed that the partial oxidation of ferrous ions to ferric ions in the solution should result in the coexistence of both ferrous and ferric ions. Therefore, we supplemented a labile supersaturated CaP solution with ferrous ions and sodium hydroxide as a lightabsorbing agent and a $\mathrm{pH}$ adjusting agent, respectively. After pulsed laser irradiation for $20 \mathrm{~min}$, CaP-based magnetic nanospheres were successfully obtained (Fig. 13a and b). These nanospheres consisted of an ACP-based matrix containing magnetite (and wüstite as well) nanoparticles dispersed throughout (Fig. 13c-e). Similar magnetic CaP particles have been fabricated by a two-step process in which magnetite nanoparticles were first prepared and subsequently treated with CaP solutions. ${ }^{96-98}$ While a small number of papers have reported the one-pot synthesis of CaP-magnetite composite particles via chemical precipitation, the reported processes required as long as a day for aging. ${ }^{99,100}$ Thus, our process represents a new practical method for the fabrication of magnetite-CaP composite nanospheres that is both simple (one-pot) and rapid (short irradiation time).

\subsection{Challenges and perspective}

As described above, laser processing in liquid is a promising tool for the surfactant-free fabrication of nanospheres of various materials. Nanospheres have a high potential as delivery carriers for therapeutic and diagnostic agents, because they are expected to be injectable and can penetrate into tiny interstices in a body owing to their nanosize. Moreover, they can be easily redispersed and cause minimal physical irritation to living organisms because of their spherical shape. Recently, CaP-based nanospheres were fabricated by the laser ablation in liquid process (Section 3.2.1) and the carbon-assisted pulsed laser melting in liquid process (Section 3.2.2) using solid CaP sources. More recently, CaP-based nanospheres were fabricated by our new physicochemical process (laser processing in labile supersaturated CaP solutions) using liquid (ion) CaP sources. As described in Section 3.3, our physicochemical process is

simple (one-pot) and rapid (short irradiation time). In addition, the source materials needed for this process are aqueous solutions of commonly used inorganic salts, and there is no need to use solid sources (either CaP targets or carbon-integrated $\mathrm{CaP}$ nanopowders) and surfactants. The chemical compositions and nanostructures of the resulting spheres are controllable by tuning the coprecipitation and irradiation conditions. Future challenges for biomedical applications include an increase in productivity (for larger scale production), in vitro and in vivo evaluation of biocompatibility, biodegradability, biological functions, and biodistribution of the spheres.

According to the proposed sphere-forming mechanism of our physicochemical process (Section 3.3), other metal ions besides ferric and ferrous ions can also be used as the light-absorbing agents and incorporated into the final CaP-based spheres. Depending on the choice of metal ions as light-absorbing agents, the resulting CaP-based spheres may exhibit different and diverse biomedical functions. Therefore, our physicochemical process has great potential as a new fabrication tool for CaP-based nanospheres for medical and dental applications.

\section{Conclusions}

The simple and rapid fabrication of CaP-based thin layers and nanospheres has been achieved using a new physicochemical process: laser processing in supersaturated $\mathrm{CaP}$ solutions, which combines a physical laser process with a chemical precipitation process. Depending on the coprecipitation and irradiation conditions, the resulting CaP-based thin layers and nanospheres exhibited a variety of physicochemical and biological properties. The developed physicochemical process has great potential as a new fabrication tool for CaP-based thin layers and nanospheres for biomedical applications.

\section{Acknowledgements}

Part of our research was supported by JSPS KAKENHI Grant Numbers JP16H03831, JP25108517 and JP15H00906, Japan, the Magnetic Health Science Foundation, Japan, and the Amada Foundation, Japan. We thank Ms Ikuko Sakamaki, Dr Yoshiki Shimizu, Dr Kenji Koga, Dr Yoshie Ishikawa, Dr Alexander Pyatenko, Dr Atsuo Ito and Dr Moumita Mahanti from AIST, Ms Nao Matsuoka and Dr Hidero Unuma from Yamagata university, and Dr Naoto Koshizaki from Hokkaido university for their contributions to our research.

\section{References}

1 S. V. Dorozhkin, Acta Biomater., 2010, 6, 715-734.

2 E. Boanini, M. Gazzano and A. Bigi, Acta Biomater., 2010, 6, 1882-1894.

3 V. Uskoković and D. P. Uskoković, J. Biomed. Mater. Res., Part B, 2011, 96, 152-191.

4 K. Fox, P. A. Tran and N. Tran, ChemPhysChem, 2012, 13, 2495-2506. 
5 M. Okada and T. Furuzono, Sci. Technol. Adv. Mater., 2012, 13, 064103.

6 M. Sadat-Shojai, M. T. Khorasani, E. Dinpanah-Khoshdargi and A. Jamshidi, Acta Biomater., 2013, 9, 7591-7621.

7 K. Lin, C. Wu and J. Chang, Acta Biomater., 2014, 10, 4071-4102.

8 S. V. Dorozhkin, Ceram. Int., 2015, 41, 13913-13966.

9 Z. Sheikh, M. N. Abdallah, A. A. Hanafi, S. Misbahuddin, H. Rashid and M. Glogauer, Materials, 2015, 8, 7913-7925.

10 S. V. Dorozhkin, Mater. Sci. Eng., C, 2015, 55, 272-326.

11 W. Habraken, P. Habibovic, M. Epple and M. Bohner, Mater. Today, 2016, 19, 69-87.

12 O. Suzuki, Acta Biomater., 2010, 6, 3379-3387.

13 S. V. Dorozhkin, Int. J. Mater. Chem., 2012, 2, 19-46.

14 D. Tadic and M. Epple, Biomaterials, 2004, 25, 987-994.

15 J. Zhang, W. Liu, V. Schnitzler, F. Tancret and J. M. Bouler, Acta Biomater., 2014, 10, 1035-1049.

16 J. H. Shepherd, D. V. Shepherd and S. M. Best, J. Mater. Sci.: Mater. Med., 2012, 23, 2335-2347.

17 J. Kolmas, E. Groszyk and D. Kwiatkowska-Różycka, BioMed Res. Int., 2014, 2014, 178123.

18 M. Šupová, Ceram. Int., 2015, 41, 9203-9231.

19 L. J. Cummings, M. A. Snyder and K. Brisack, Methods Enzymol., 2009, 463, 387-404.

20 R. Freitag and F. Hilbrig, Biotechnol. J., 2012, 7, 90-102.

21 M. Vila, S. Sánchez-Salcedo and M. Vallet-Regí, Inorg. Chim. Acta, 2012, 393, 24-35.

22 P. Chand and Y. B. Pakade, Environ. Sci. Pollut. Res., 2015, 22, 10919-10929.

23 K. Khosravi-Darani, M. R. Mozafari, L. Rashidi and M. Mohammadi, Acta Med. Iran., 2010, 48, 133-141.

24 D. Lee, K. Upadhye and P. N. Kumta, Mater. Sci. Eng., B, 2012, 177, 289-302.

25 A. Oyane, X. Wang, Y. Sogo, A. Ito and H. Tsurushima, Acta Biomater., 2012, 8, 2034-2046.

26 M. Zhang and K. Kataoka, Nano Today, 2009, 4, 508-517.

27 M. Epple, K. Ganesan, R. Heumann, J. Klesing, A. Kovtun, S. Neumann and V. Sokolova, J. Mater. Chem., 2010, 20, 18-23.

28 S. S. Syamchand and G. Sony, Microchim. Acta, 2015, 182, 1567-1589.

29 S. C. G. Leeuwenburgh, J. G. C. Wolke, J. A. Jansen and K. de Groot, in Bioceramics and their clinical applications, ed. T. Kokubo, Woodhead Pub., Cambridge, England, 2008, vol. 20, pp. 464-484.

30 R. A. Surmenev, M. A. Surmeneva and A. A. Ivanova, Acta Biomater., 2014, 10, 557-579.

31 S. R. Paital and N. B. Dahotre, Mater. Sci. Eng., R, 2009, 66, 1-70.

32 R. A. Surmenev, Surf. Coat. Technol., 2012, 206, 2035-2056.

33 S. Shadanbaz and G. J. Dias, Acta Biomater., 2012, 8, 20-30.

34 Y. H. Liang, C. H. Liu, S. H. Liao, Y. Y. Lin, H. W. Tang, S. Y. Liu, I. R. Lai and K. C. W. Wu, ACS Appl. Mater. Interfaces, 2012, 4, 6720-6727.

35 B. P. Bastakoti, M. Inuoe, S. Yusa, S. H. Liao, K. C. W. Wu, K. Nakashima and Y. Yamauchi, Chem. Commun., 2012, 48, 6532-6534.
36 B. P. Bastakoti, Y. C. Hsu, S. H. Liao, K. C. W. Wu, M. Inoue, S. Yusa, K. Nakashima and Y. Yamauchi, Chem. - Asian J., 2013, 8, 1301-1305.

37 Y. H. Yang, C. H. Liu, Y. H. Liang, F. H. Lin and K. C. W. Wu, J. Mater. Chem. B, 2013, 1, 2447-2450.

38 A. Oyane, I. Sakamaki, Y. Shimizu, K. Kawaguchi and N. Koshizaki, J. Biomed. Mater. Res., Part A, 2012, 100, 2573-2580.

39 A. Oyane, I. Sakamaki, Y. Shimizu, K. Kawaguchi, Y. Sogo, A. Ito and N. Koshizaki, Key Eng. Mater., 2013, 529-530, 217-222.

40 A. Oyane, I. Sakamaki, A. Pyatenko, M. Nakamura, Y. Ishikawa, Y. Shimizu, K. Kawaguchi and N. Koshizaki, RSC Adv., 2014, 4, 53645-53648.

41 A. Oyane, N. Matsuoka, K. Koga, Y. Shimizu, M. Nakamura, K. Kawaguchi, N. Koshizaki, Y. Sogo, A. Ito and H. Unuma, Colloids Interface Sci. Commun., 2015, 4, 5-9.

42 M. Mahanti, M. Nakamura, A. Pyatenko, I. Sakamaki, K. Koga and A. Oyane, J. Phys. D: Appl. Phys., 2016, 49, 304003.

43 M. Nakamura, A. Oyane, I. Sakamaki, Y. Ishikawa, Y. Shimizu, K. Koga, K. Kawaguchi and N. Koshizaki, RSC Adv., 2014, 4, 38442-38445.

44 M. Nakamura, A. Oyane, I. Sakamaki, Y. Ishikawa, Y. Shimizu and K. Kawaguchi, Phys. Chem. Chem. Phys., 2015, 17, 8836-8842.

45 Y. Liu, G. Wu and K. de Groot, J. R. Soc., Interface, 2010, 7, S631-S647.

46 X. Wang, A. Ito, X. Li, Y. Sogo and A. Oyane, Biofabrication, 2011, 3, 022001.

$47 \mathrm{X}$. Wang, A. Oyane and A. Ito, in Advances in calcium phosphate biomaterials, ed. B. Ben-Nissan, Springer-Verlag, Berlin Heidelberg, Germany, 2014, vol. 2, pp. 171-197.

48 T. Kokubo and H. Takadama, Biomaterials, 2006, 27, 2907-2915.

49 A. C. Tas, Acta Biomater., 2014, 10, 1771-1792.

50 L. Pramatarova, E. Pecheva, T. Petrov, A. Kondyurin, R. Pramatarova and N. Minkovski, Vacuum, 2004, 76, 339-342.

51 L. Pramatarova, E. Pecheva, D. Dimova-Malinovska, R. Pramatarova, U. Bismayer, T. Petrov and N. Minkovski, Vacuum, 2004, 76, 135-138.

52 L. Pramatarova, E. Pecheva, R. Presker, M. T. Pham, M. F. Maitz and M. Stutzmann, Eur. Cells Mater., 2005, 9, 9-12.

53 E. Pecheva, T. Petrov, C. Lungu, P. Montgomery and L. Pramatarova, Chem. Eng. J., 2008, 137, 144-153.

54 B. H. Lee, A. Oyane, H. Tsurushima, Y. Shimizu, T. Sasaki and N. Koshizaki, ACS Appl. Mater. Interfaces, 2009, 1, 1520-1524.

55 T. Kasuga, H. Kondo and M. Nogami, J. Cryst. Growth, 2002, 235, 235-240.

56 X. Liu, X. Zhao, B. Li, C. Cao, Y. Dong, C. Ding and P. K. Chu, Acta Biomater., 2008, 4, 544-552.

57 A. Guha, S. Nayar and H. N. Thatoi, Bioinspiration Biomimetics, 2010, 5, 024001.

58 H. Zhou, M. Nabiyouni and S. B. Bhaduri, Mater. Sci. Eng., $C, 2013,33,4435-4443$.

59 H. Zhou, V. K. Goel and S. B. Bhaduri, Mater. Lett., 2014, 125, 96-98.

60 Y. Ren, H. Zhou, M. Nabiyouni and S. B. Bhaduri, Mater. Sci. Eng., C, 2015, 49, 364-372. 
61 M. Uchida, A. Oyane, H. M. Kim, T. Kokubo and A. Ito, Adv. Mater., 2004, 16, 1071-1074.

62 H. McDowell, T. M. Gregory and W. E. Brown, J. Res. Natl. Bur. Stand., Sect. A, 1977, 81, 273-281.

63 M. R. Christoffersen, J. Christoffersen and W. Kibalczyc, J. Cryst. Growth, 1990, 106, 349-354.

64 A. Ito, H. Kawamura, M. Otsuka, M. Ikeuchi, H. Ohgushi, K. Ishikawa, K. Onuma, N. Kanzaki, Y. Sogo and N. Ichinose, Mater. Sci. Eng., C, 2002, 22, 21-25.

65 Y. Sogo, A. Ito, T. Matsuno, A. Oyane, G. Tamazawa, T. Satoh, A. Yamazaki, E. Uchimura and T. Ohno, Biomed. Mater., 2007, 2, 116-123.

66 X. Wang, A. Ito, Y. Sogo, X. Li and A. Oyane, Acta Biomater., 2010, 6, 962-968.

67 C. de Paula Eduardo, P. M. de Freitas, M. Esteves-Oliveira, A. C. C. Aranha, K. M. Ramalho, A. Simões, M. S. Bello-Silva and J. Tunér, Lasers Med. Sci., 2010, 25, 781-792.

68 S. K. Houston, C. C. Wykoff, A. M. Berrocal, D. J. Hess and T. G. Murray, Lasers Med. Sci., 2013, 28, 1025-1034.

69 K. França, A. Chacon, J. Ledon, J. Savas, J. Izakovic and K. Nouri, Lasers Med. Sci., 2013, 28, 1197-1204.

70 P. M. S. L. Shanthi, R. V. Mangalaraja, A. P. Uthirakumar, S. Velmathi, T. Balasubramanian and M. Ashok, J. Colloid Interface Sci., 2010, 350, 39-43.

71 F. Ye, H. Guo, H. Zhang and X. He, Acta Biomater., 2010, 6, 2212-2218.

72 H. Zhou and S. Bhaduri, J. Biomed. Mater. Res., Part B, 2012, 100, 1142-1150.

73 C. Qi, Y. J. Zhu, X. Y. Zhao, B. Q. Lu, Q. L. Tang, J. Zhao and F. Chen, Chem. - Eur. J., 2013, 19, 981-987.

74 J. Zhao, Y. J. Zhu, J. Q. Zheng, F. Chen and J. Wu, Microporous Mesoporous Mater., 2013, 180, 79-85.

75 P. Rouhani, N. Taghavinia and S. Rouhani, Ultrason. Sonochem., 2010, 17, 853-856.

76 A. Fojtik and A. Henglein, Ber. Bunsen-Ges. Phys. Chem., 1993, 97, 252-254.

77 G. Yang, Prog. Mater. Sci., 2007, 52, 648-698.

78 V. Amendola and M. Meneghetti, Phys. Chem. Chem. Phys., 2009, 11, 3805-3821.

79 H. Zeng, X. W. Du, S. C. Singh, S. A. Kulinich, S. Yang, J. He and W. Cai, Adv. Funct. Mater., 2012, 22, 1333-1353.

80 S. W. Mhin, J. H. Ryu, K. M. Kim, G. S. Park, H. W. Ryu, K. B. Shim, T. Sasaki and N. Koshizaki, Appl. Phys. A: Mater. Sci. Process., 2009, 96, 435-440.
81 M. Boutinguiza, J. Pou, F. Lusquiños, R. Comesaña and A. Riveiro, Appl. Surf. Sci., 2011, 257, 5195-5199.

82 M. Boutinguiza, J. Pou, F. Lusquiños, R. Comesaña and A. Riveiro, Phys. Procedia, 2011, 12, 54-59.

83 H. Wang, A. Pyatenko, K. Kawaguchi, X. Li, Z. SwiatkowskaWarkocka and N. Koshizaki, Angew. Chem., Int. Ed., 2010, 49, 6361-6364.

84 Y. Ishikawa, Y. Shimizu, T. Sasaki and N. Koshizaki, Appl. Phys. Lett., 2007, 91, 161110.

85 H. Wang, N. Koshizaki, L. Li, L. Jia, K. Kawaguchi, X. Li, A. Pyatenko, Z. Swiatkowska-Warkocka, Y. Bando and D. Golberg, Adv. Mater., 2011, 23, 1865-1870.

86 X. Li, A. Pyatenko, Y. Shimizu, H. Wang, K. Koga and N. Koshizaki, Langmuir, 2011, 27, 5076-5080.

87 Z. Swiatkowska-Warkocka, K. Koga, K. Kawaguchi, H. Wang, A. Pyatenko and N. Koshizaki, RSC Adv., 2013, 3, 79-83.

88 T. Tsuji, T. Yahata, M. Yasutomo, K. Igawa, M. Tsuji, Y. Ishikawa and N. Koshizaki, Phys. Chem. Chem. Phys., 2013, 15, 3099-3107.

89 M. Nakamura, A. Oyane, I. Sakamaki, Y. Shimizu, K. Koga and N. Koshizaki, RSC Adv., 2015, 5, 22620-22624.

90 X. Li, Y. Shimizu, A. Pyatenko, H. Wang and N. Koshizaki, J. Mater. Chem., 2011, 21, 14406-14409.

91 X. Li, Y. Shimizu, A. Pyatenko, H. Wang and N. Koshizaki, Nanotechnology, 2012, 23, 115602.

92 M. S. A. Johnsson and G. H. Nancollas, Crit. Rev. Oral Biol. Med., 1992, 3, 61-82.

93 M. Mahmoudi, S. Sant, B. Wang, S. Laurent and T. Sen, Adv. Drug Delivery Rev., 2011, 63, 24-46.

94 L. H. Reddy, J. L. Arias, J. Nicolas and P. Couvreur, Chem. Rev., 2012, 112, 5818-5878.

95 X. Ren, H. Chen, V. Yang and D. Sun, Front. Chem. Sci. Eng., 2014, 8, 253-264.

96 L. Dong, Z. Zhu, Y. Qiu and J. Zhao, Chem. Eng. J., 2010, 165, 827-834.

97 Y. Liu, H. Zhong, L. Li and C. Zhang, Mater. Res. Bull., 2010, 45, 2036-2039.

98 H. Yang, S. Masse, H. Zhang, C. Helary, L. Li and T. Coradin, J. Colloid Interface Sci., 2014, 417, 1-8.

99 H. C. Wu, T. W. Wang, J. S. Sun, W. H. Wang and F. H. Lin, Nanotechnology, 2007, 18, 165601.

100 E. B. Ansar, M. Ajeesh, Y. Yokogawa, W. Wunderlich and H. Varma, J. Am. Ceram. Soc., 2012, 95, 2695-2699. 